\title{
El conflicto mapuche como lucha por el reconocimiento: La necesidad de una nueva clave de lectura
}

The mapuche conflict as fight for recognition: The need for a new theoretical framework

\author{
Cristobal Balbontin-Gallo*
}

RESUMEN: El presente ensayo tiene como contexto la agudización del conflicto entre comunidades mapuche y el Estado en las regiones de la Araucanía y Los Ríos, lo que da cuenta de una falta de marco teórico de lectura adecuado de este conflicto que permita al Estado elaborar políticas públicas que permitan encontrar una vía de solución pacífica y legítima al conflicto. A partir de lo anterior, este ensayo busca argumentar en torno a la pertinencia de aplicar la teoría del reconocimiento de Axel Honneth a fin de revisar el modelo de justicia social que sirve de base al diseño de las políticas públicas en relación con este pueblo originario.

Palabras clave: identidad, mapuche, conflicto, justicia social, políticas públicas

ABSTRACT: The present essay has as context the worsening of the conflict between Mapuche communities and the State in the regions of Araucanía and Los Ríos, which accounts for a lack of a theoretical framework for an adequate reading of this struggle that allows the State to elaborate public policies that let us find a way of peaceful and legitimate solution. From the above, this essay seeks to argue about the relevance of applying the theory of recognition of Axel Honneth in order to review the model of social justice that serves as framework for the design of public policies in relation to this original people.

Key words: identity, mapuche, social justice, conflict, public policies

Recibido: 7 noviembre 2018 Aceptado: 7 enero 2019

\section{Introducción}

Resulta evidente. El conflicto que enfrenta el pueblo mapuche en las regiones de la Araucanía y Los Ríos, da cuenta de una deficiencia de las políticas públicas del Estado en su relación con este pueblo indígena. Existe, en efecto, una cierta incapacidad del Estado para abordar el conflicto en sus causas, lo que implica que su aproximación al conflicto vaya quedando reducida a una actividad puramente represiva. Ello a su vez supone el riesgo de reducir este conflicto social a una hipótesis puramente criminal, lo que configura un verdadero "Derecho penal del enemigo". En este sentido, la conferencia episcopal (2016) ha criticado la incapacidad del Estado para encontrar una vía de solución pacífica al

\footnotetext{
* Doctor en filosofía por la Universität J.W. Goethe Frankfurt am Main y Université Paris-Nanterre, Investigador asociado de IREPH Université Paris-Nanterre, Profesor auxiliar de la Universidad Austral, Helena Haverbeck s/n, Campus Isla Teja, Valdivia, Chile. Email: cbalbonting@gmail.com
} 
conflicto $^{1}$. Todo indica que una parte de la historiografía nacional tendría razón ${ }^{2}$, cuando constatamos que el ejercicio del ius puniendi alimenta una cierta incapacidad histórica para superar la violencia. Lo anterior implica, en consecuencia, la necesidad de un nuevo marco teórico de lectura de este conflicto que permita al Estado encontrar una vía de solución pacífica y legítima al conflicto con este pueblo originario. En este sentido, la teoría del reconocimiento de Axel Honneth puede ofrecer una vía de solución normativa a esta insuficiencia política. La tesis que moviliza el presente artículo es que lo que está en cuestión no es sólo la justa reasignación de bienes y servicios, sino que este conflicto también debe ser entendido a partir de una experiencia histórica de humillación o agravio moral que impulsa a los mapuches a luchar por el reconocimiento y la restauración moral de su dignidad colectiva. Este artículo, no obstante, no asume como propósito indagar en formas de reconocimiento constitucional de un sujeto político ni en el reconocimiento puramente formal en la ley de la condición indígena, sino que busca -en lo fundamental- revisar el modelo de justicia social que sirve de base al diseño de las políticas públicas en relación con este pueblo originario.

\section{La relevancia del contexto histórico para comprender el conflicto}

Cualquier esfuerzo reflexivo debe hacerse cargo del status quo del casus belli: los mapuches son el grupo social más discriminado, pobre y marginalizado de acuerdo a la encuesta CASEN (2015) ${ }^{3}$. Pero determinar dicha experiencia de exclusión, presupone necesariamente hacerse cargo de la génesis histórica del conflicto que surge con la ocupación de la Araucanía y continua con la política de colonización y reparto de tierras que se perpetúa en el siglo XX. Desde sus inicios al Estado le persigue una contradicción en su relación con el pueblo mapuche. Por una parte, la construcción del imaginario patriótico se alimenta del mito indómito y "valeroso de la sangre araucana" a la que se debe emancipar de la tutela de la corona española para incorporarlos a la nación ${ }^{4}$. Las leyes liberales que Mariano Egaña impulsó en 1813 buscaban liberar a los indígenas de la sumisión a la corona ibérica y facilitar al ingreso de los indígenas al mercado de tierras. El reconocimiento de la ciudadanía para los indígenas, implicó materializar uno de los ideales republicanos: el principio de igualdad de todos los hombres bajo una norma general, impersonal y sin distinciones ${ }^{5}$. Pero al mismo tiempo se consagraba una primera forma de violencia: la asimilación e invisibilización de los mapuches bajo una categoría general. Esta primera forma de asimilación fue entonces política. En efecto, el reglamento de 1813 -dictado por la junta de gobierno- fue la primera iniciativa legislativa referida a los indígenas, la que junto con proclamar la "fraternidad, igualdad y prosperidad de los indios", proponía el abandono de los campos y pueblos de indios para residir en villas a fin de gozar los mismos derechos de ciudadanía que el resto de los chilenos (artículo $1^{\circ}$, Reglamento Ley de 1813). De este modo las leyes liberales que Mariano Egaña impulsó en 1813 buscaban implícitamente- facilitar el ingreso de los indígenas al mercado común de tierras al amparo del principio republicano de igualdad entre los ciudadanos.

A esta primera forma de asimilación formal, le seguirá una forma de asimilación material. El contexto espiritual del pensamiento evolucionista que desarrolla Charles Darwin en biología, y que rápidamente alimentó el evolucionismo social presente en la filosofía positivista de August Comte como en la antropología colonial de Lewis Morgan y Edward Burnett Tylor, inspiró a políticos e intelectuales chilenos del siglo XIX, como queda de manifiesto -por ejemplo- en el pensamiento de Diego Barros Arana y su Historia General de Chile. Este mismo contexto espiritual es el que se encuentra a la base del

\footnotetext{
${ }^{1}$ Declaración de la $111^{\circ}$ Asamblea Plenaria de la Conferencia Episcopal de Chile.

2 Salazar, Gabriel, Labradores, Peones y proletarios, 1985, Santiago, Ediciones Sur.

3 Encuesta Nacional de Caracterización Socioeconómica correspondiente al año 2015. Disponible en: http://observatorio.ministeriodesarrollosocial.gob.cl/casen-multidimensional/casen/docs/CASEN_2015.pdf

${ }_{4}$ Bengoa, José, Historia del Pueblo Mapuche (Siglo XIX y XX), Santiago, Chile, LOM ediciones, 2000, p.28.

5 Sieyès, Emmanuel-Joseph, Qu'est-ce qu'est le tiers état?, Paris, ed. Du Boucher, 2002, p.5.
} 
relato a partir del cual la campaña de pacificación de la Araucanía se transforma en una necesidad de Estado. Para la sociedad agraria del valle central, que mira a Europa, era forzoso oponer el ideal civilizador a la barbarie. Se impone entonces la idea de una asimilación cultural asociada al poder transformador de las ciencias sobre toda realidad social. Dicho proceso civilizador de los mapuches debía comenzar ante todo por la tierra que constituye -doblemente- un factor de producción a la vez que un agente socializador ${ }^{6}$. Así se impone la tesis del tránsito forzoso de los mapuches desde una economía ganadera basada en el pastoreo transhumante de grandes extensiones a una agricultura sedentaria reducida, a la vez que se busca incorporar nuevas tierras desocupadas a la economía nacional 7 .

De este modo, ya con anterioridad a la ocupación militar de la Araucanía de 1860, el año 1852 se dicta la ley que crea la provincia de Arauco y que incluye los territorios indígenas, declarando el propósito de su "más pronta civilización" (artículo 3). Por su parte a partir del año 1866 -con posterioridad a la invasión militar- se dicta la primera de las leyes de ocupación. Dicho precepto legal -con algunas modificaciones introducidas en 1874 y 1883 - contempló que los terrenos de los indígenas fueran deslindados por la "Comisión Radicadora de Indígenas", encargada de ubicar a los habitantes originales. Para ello los indígenas debían acreditar posesión efectiva y continua, en cuyo caso contrario las tierras serían reputadas como terrenos baldíos (res nullius) y, por consiguiente, declaradas propiedad fiscal. Una vez deslindadas esas tierras, estas fueron otorgadas de forma comunitaria en favor de los indígenas a través títulos de merced $^{8}$. A su vez las tierras reputadas fiscales -de acuerdo a este procedimiento- fueron entregadas a colonos extranjeros y nacionales. De este modo se materializó el proceso de reducción y confiscación de tierras originalmente indígenas, cuya área resultante fue equivalente a un $6,39 \%$ del área que ancestralmente ocupaban al sur de Bio-Bío\%. Por esta vía se liquidó el espacio territorial histórico del pueblo mapuche, la forma de vida asociada a un territorio extenso, de bordes imprecisos y -por otra parte- se limitó su propiedad a tierras de labranzas alrededor de viviendas destinadas a la habitación, con el consecuente empobrecimiento material, primero, y la perdida cultural, enseguida, derivada al cambio de sistema económico agrícola. A lo anterior se suma el hecho que las tierras donde se produjo la radicación correspondía a viviendas y plantaciones, omitiendo territorios que habían sido ocupados para la pesca, la caza y la recolección como las zonas remotas y de difícil acceso (como aquellas que se encontraban al sur de Valdivia y Osorno), con lo cual una parte importante de la población nunca recibió un título de merced $^{10}$. Además, la radicación de los mapuches se hizo sin respetar la forma de organización social tradicional de este pueblo como el Lof, el Rewe o el Aillarewe, lo que motivó una serie de conflictos al interior de las comunidades ${ }^{11}$. De este modo se deterioró severamente la capacidad tradicional de organización política de los mapuches en liderazgos espontáneos alrededor de lonkos o caciques. Por otra parte, los indígenas sufrieron la usurpación de sus tierras a través de inscripciones de títulos de papel. Concretamente esto fue el producto no sólo del proceder malicioso de colonos inescrupulosos, sino

\footnotetext{
${ }^{6}$ Marx, Karl, Grundrisse der Kritik der Politischen Ökonomie, Berlín, Dietz, 1953.

7 Pinto, Julio. 2000. De la inclusión a la exclusión. La formación del estado, la nación y el pueblo mapuche. Santiago: Instituto de Estudios Avanzados, Universidad de Santiago, p.131.

8 Aylwin, José, Meza-Lopehandia, Matías, \& Yáñez, Nancy, Los pueblos indígenas y el derecho. Santiago, LOM Ediciones, 2013.

9 González, Héctor, "Propiedad Comunitaria o individual. Las Leyes indígenas y el pueblo mapuche". Nütram, año II, N³, 1986, Santiago, Centro Ecuménico Diego de Medellín.

${ }^{10}$ Comisión de Verdad Histórica y Nuevo Trato, Informe de la Comisión Verdad Histórica y Nuevo Trato de los Pueblos Indígenas. Disponible en: http://www.memoriachilena.cl/602/articles-122901_recurso_2.pdf

${ }_{11}$ Comisión de Verdad Histórica y Nuevo Trato, op. cit. En efecto, la base de la organización social mapuche es el lof. En él un grupo familiar de 3 o 4 generaciones -emparentados por un ancestro en común- vive y se organiza en torno a un jefe de familia o lonko. Los lof a su vez se agrupan para formar los rewe, que son sociedades donde aún se mantiene el vínculo familiar de carácter patrilineal. En estos se elige a su vez los ülmen fütra lonko que constituye su autoridad. A través de los ayllarrewe, los rewe se pueden agrupar a su vez en organizaciones sociales más amplias que constituyen los fïtal mapu que constituyen la organización social y política más amplia en tiempo de paz. Sin perjuicio de lo anterior, si bien en el lof se manifiesta el elemento personal como predominante de la organización social (lof che), por su conexión territorial adquiere relevancia la inserción en el espacio natural (lof mapu) para efectos de la construcción social. Además, el fortalecimiento de los lazos sociales se materializa en los lof küdow, consistentes en una forma económica de trabajo comunitario retribuido con actividades festivas.
} 
además de límites imprecisos que establecían los títulos de merced, en que los planos poco o nada correspondían a la topografía de la zona. Como resultado el propietario de "papel" se instalaba luego de la inscripción, con el consecuente lanzamiento de la familia indígena devenida -en el intertanto- ocupante ilegal. Esta situación perturbó de forma tan sensible a los indígenas que motivó la visita de una comisión parlamentaria a las zonas afectadas ${ }^{12}$. Con posterioridad, entre los años 1901 a 1905, durante el gobierno del presidente Riesco, se sumaron tierras indígenas al reparto de concesiones, sobre las cuales se produjo una superposición de derechos sobre los recursos naturales de parte de las empresas concesionarias y los terrenos de los indígenas que generó un problema adicional al conflicto generado por la usurpación. Esta situación motivó desde 1925 la dictación de una serie de leyes sobre constitución de propiedad austral, que intentaron poner un mínimo de orden en uno de los asuntos más desordenados que existía en el país: la situación de las tierras indígenas. A través de ellas se otorgaba competencia a las Cortes de Apelaciones de Temuco y Valdivia para conocer las contiendas entre el Fisco y los particulares que se habían hecho de títulos de papel. Sin embargo, el articulado excluía a los indígenas, quienes continuarían siendo radicados conforme a las leyes anteriormente mencionadas.

Frente a la situación anteriormente descrita, el año 1928 se dictó el Decreto No1.851, que disponía un tribunal especial encargado de restituir los terrenos usurpados a los indígenas en aquella parte en que los títulos de mereced eran ocupados por no indígenas (artículo 23). No obstante, la Ley No4.802 de 1930, siguiendo el precedente de la Ley N4.169 de 1927, estableció cinco juzgados de indios encargados de dividir las comunidades indígenas asignadas en los títulos de merced a iniciativa de los integrantes de la comunidad o del tribunal especial creado para la restitución de terrenos, incluso contra la voluntad de los comuneros. El propósito era promover la división de las tierras reduccionales como forma de incorporar a los indígenas al sistema de propiedad individual y a la libre circulación de los bienes, a través de consolidación de la libertad para enajenar o gravar los lotes resultantes de la división, previa autorización del juez de indios. Por su parte, el Decreto con Fuerza de Ley No 266 y el Decreto Supremo $\mathrm{N}^{\circ}$ 4.111, ambos de 1931, vinieron a facilitar aún más el proceso al establecer que los juzgados de indios podían proceder a la división de las comunidades si lo solicitaban simplemente un tercio de sus miembros. Los predios individuales resultantes podrían ser enajenados o gravados libremente, es decir, sin necesidad de autorización previa del juzgado de indios. Por otra parte, a fin de regularizar la propiedad al sur del Río Malleco, se dictó la Ley No 1.600 (de Propiedad Austral), la que conjuntamente con el Decreto con Fuerza de Ley $\mathrm{N}^{\circ}$ 266, del mismo año, buscó la regularización de la propiedad no indígena a través de la presentación de títulos y la acreditación de la posesión material de los terrenos, continua e ininterrumpida, durante diez años que luego fueron rebajados a dos años. Esta legislación facilitó la desposesión de los indígenas en estas zonas ya que se presentaban a los ocupantes indígenas tradicionales como inquilinos para acreditar la posesión y lograr justamente la regularización de una propiedad particular constituida en base a una tierra indígena ${ }^{13}$.

Fue tan sólo en 1940, con la dictación de la Ley Nº 6.519 y sus sucesivas prórrogas de la limitación de la capacidad para enajenar de los indígenas, que comenzó un período de una cierta protección de la tierra indígena, que duró hasta 1947 con la dictación de la Ley No 8.736 que les reconoció plena capacidad para celebrar actos y contratos sobre sus tierras comunitarias como individuales. No obstante, dicho estatuto de protección se vio fortalecido en 1953 por la extensión de la exención tributaria a las tierras de propiedad mapuche y la creación inédita -hasta entonces- de una entidad gubernamental encargada de los asuntos indígenas: la Dirección de Asuntos Indígenas. A su vez el Decreto con Fuerza de Ley $\mathrm{N}^{\circ}$ 65, de 1960, y la Ley No14.511, de 1961, dispusieron la posibilidad de otorgar títulos gratuitos en tierras consideradas como fiscales disponibles entre Bio-Bío y Chiloé, entre otros, a los indígenas. La segunda norma dispuso -por primera vez- que los juzgados de letras de indios tendrían jurisdicción no sólo para

\footnotetext{
12 Bengoa, José, op.cit.

13 Comisión de Trabajo Autónomo Mapuche, "Informe de la Comisión de Trabajo Autónomo Mapuche”, recuperado el 8 de octubre de 2018. Disponible en: http://biblioteca.serindigena.org/libros_digitales/cvhynt/
} 
la división de comunidades sino también para llevar a cabo restitución de tierras indígenas. Adicionalmente se dispuso que la enajenación o gravamen de tierras fuera con autorización de dicha sede jurisdiccional. A pesar de que dicha legislación tuvo cierto impacto en el otorgamiento de tierras a los indígenas ${ }^{14}$, ella no impidió el proceso de desintegración y usurpación de las tierras reduccionales, como consta en las conclusiones de los dos congresos nacionales mapuches que tuvieron lugar en 1969 y 1970. Fue tan sólo a través de la Ley No16.640, de Reforma Agraria, y en particular la Ley No17.729, de 1972, que se sentaron las bases normativas para la redistribución de la propiedad de la tierra, haciendo posible la entrega de tierras a los indígenas. No obstante, con el golpe de estado de 1973 el impulso del proceso de reforma agraria se vio completamente contrahecho.

A partir de 1979 el proceso de asimilación cultural se profundiza. La división de las comunidades y la consolidación de propiedades individuales desafectadas de su condición indígena vuelve a imponerse con fuerza con la dictación del Decreto Ley N $\mathrm{N}^{\circ} 2.568$, que contempló la posibilidad para que cualquier ocupante de una reserva, indígena o no indígena, solicitara la división de las tierras de una reducción a través de un procedimiento legal expedito que, una vez aprobado, contemplaba la asignación de hijuelas de propiedad privada individual a quienes habitaban en ella. Del mismo modo, el procedimiento presuponía la liquidación de la comunidad una vez terminada la división y la determinación de los derechos de cada uno de los comuneros, así como el pago de los derechos de aquellos comuneros que por no estar presentes- no se les adjudicaron tierras. Como consecuencia de lo anterior, las tierras resultantes no serían consideradas indígenas como tampoco lo serían los adjudicatarios de dichas hijuelas. Si bien esta norma contemplaba una prohibición para vender durante 20 años las hijuelas resultantes, se verificó un número importante de usurpaciones a través de contratos fraudulentos que contemplaban arrendamientos por 99 años o la cesión de acciones y de derechos. Junto con poner fin al Instituto de Desarrollo Indígena, la norma apuntaba en lo fundamental a terminar con el estatus legal de la condición "indígena", a la vez que incorporarlos a un principio de libre circulación de los bienes y, consecuentemente, a un paradigma económico de corte individualista; eliminando de esta forma el conato de excepción cultural sobre el cual se construye la diversidad de formas de vida. A ello se le debe sumar la dictación del DL No 701 el año 1974, que estableció un subsidio a las plantaciones forestales -principalmente de especies foráneas como pino radiata y eucaliptus- que opero como un fuerte incentivo a la actividad económica extractiva de bosques y que trajo -como contrapartida- no sólo la degradación del medio ambiente con la tala masiva de bosque nativo y su sustitución, sino que además afectó la relación del mapuche sobre la naturaleza circundante donde se desenvuelve cotidianamente su forma de vida. ${ }^{15}$

\section{Entre dos conceptos de justicia}

Es a la vista del precedente histórico descrito con anterioridad, que se dicta la Ley $\mathrm{N}^{\circ} 19.253$ sobre Protección, Fomento y Desarrollo Indígena, inspirada en una concepción multicultural de la nación a la vez que protectora de las minorías étnicas originales del país. Consistente con dichos principios, el artículo $1^{\circ}$ de la ley declara que es deber del Estado "respetar, proteger y promover el desarrollo de los indígenas, sus culturas, familias y comunidades (...)". Para ello la ley reconoce las etnias indígenas, así como a las comunidades y asociaciones, estableciendo para ello un procedimiento para dotarlos de personalidad jurídica. Además, comprende el establecimiento de la Corporación Nacional de Desarrollo Indígena (CONADI) junto al desarrollo de disposiciones y fuentes de financiamiento tendientes a la

\footnotetext{
14 Aylwin et al., op.cit.

15 Carrasco, Noela, "Trayectoria de las relaciones entre empresas forestales y comunidades mapuche en Chile" en Polis [on line], 31 | 2012, publicado el 12 de diciembre de 2012, consultado el 21 de diciembre de 2018. URL: http://journals.openedition.org/polis/3768
} 
afirmación cultural, ya sea través de la inclusión del idioma indígena en la educación local, la difusión de manifestaciones culturales y artísticas como el otorgamiento de becas indígenas, entre otras medidas. Por su parte, el artículo 34 de la ley contempla la consulta de los indígenas por parte de los servicios de la Administración del Estado cuando se trate de materias que tengan injerencia con cuestiones indígenas. Por último, la ley conceptualiza las Áreas de Desarrollo Indígena como espacios territoriales donde el Estado debe focalizar la atención de sus servicios público en beneficio de un desarrollo armónico de los indígenas y sus comunidades.

Consistente con la declaración del artículo $1^{\circ}$ de que "la tierra es el fundamento principal de la existencia y cultura indígena", la ley dispone que las tierras indígenas no podrán ser enajenadas, gravadas ni embargadas salvo entre comunidades o personas de la misma etnia, a la vez que limita la celebración de arrendamientos como la división de tierras comunitarias. Para estos efectos identifica las tierras indígenas estableciendo un registro de tierras, en que se inscriben no sólo las tierras de personas o comunidades que actualmente ocupan -en propiedad o posesión las tierras-, sino que además considera aquellas que sean declaradas por los tribunales como pertenecientes a indígenas y las que los indígenas reciban a futuro a título gratuito del Estado. De conformidad a lo anterior, se estatuye el Fondo de Tierras y Aguas como mecanismo para restituir tierras a los indígenas, el que busca -en lo fundamental- financiar la adquisición de tierras o la ampliación de tierras y comunidades existentes. Asimismo, el Fondo también ha permitido financiar la adquisición de derechos de agua en favor de las comunidades. Por otra parte, la ley No20.249 de 2008, que crea el Espacio Costero Marino de los Pueblos Originarios, le confiere la administración de porciones del borde costero a asociaciones y comunidades que invocan el uso consuetudinario, la que se materializa precisamente a través de la constitución de concesiones.

Sin embargo, ni la intervención preferente de los servicios públicos ni el establecimiento del Fondo de Tierras y Aguas ha logrado resolver de forma satisfactoria las demandas de comunidades y organizaciones mapuches. En buena medida la lógica del Fondo de Aguas, en particular el régimen de concesiones a favor de los indígenas, sigue siendo solidario de una forma cultural ajena al universo indígena que se basa -en lo sustancial- en una relación puramente económica con la naturaleza y en una ontología social sustentada en un solipsismo individualista que desprovee a los individuos de los lazos sociales asociados a la naturaleza en la constitución de su identidad personal. Del mismo modo la quema de iglesias en la región de la Araucanía es el síntoma de un malestar que no es de orden patrimonial y que no se logra solucionar adecuadamente a través de los actuales dispositivos organizados por la ley indígena. El problema radica en una concepción de justicia implícita al Fondo de Tierras y Aguas que reduce a una clave económica la lectura de los conflictos sociales y que entiende, en consecuencia, que el conflicto mapuche encuentra sus causas, por una parte, en la pobreza y falta de acceso a bienes y servicios y, por otra parte, en un problema de justicia social que surge con la usurpación histórica de tierras ancestrales que debe ser resuelta -consecuentemente- a través de la restitución de dichas tierras a sus dueños originales.

Este marco teórico de lectura de los conflictos sociales es solidario de una tradición filosófica que va desde Aristóteles hasta Dworkin y que entiende que las demandas de justicia social tienen su origen en una indebida distribución de bienes. En efecto, Aristóteles en el libro V de la Ética a Nicómaco distingue la justicia distributiva (nemêtikon dikaion) de la justicia conmutativa (diorthotikon dikaion), como aquella que toca a la cosa pública y que consiste en la forma de repartir cargas y beneficios a aquellos que viven en una misma polis en proporción geométrica de forma de tratar a los iguales como iguales y a los desiguales como desiguales. El utilitarismo formulado por Bentham y corregido por Stuart Mill, mantiene parcialmente el presupuesto aristotélico bajo la premisa de que la distribución de bienes debe realizarse en función de la capacidad de cada individuo para obtener su satisfacción personal, logrando la mayor utilidad para el mayor número de individuos. Marx -como el liberalismo radical- abandona, por distintos motivos desde luego, estos presupuestos clásicos de la justicia social. Marx sostiene que la distribución del ingreso y de los medios de consumo procede en definitiva de las estructuras de organización 
productiva y concretamente de la propiedad de los medios de producción ${ }^{16}$, con lo cual las contradicciones sociales solo se resuelven con la reasignación de la propiedad de los factores de producción. Por su parte, el liberalismo radical de Hayek y Nozick rechaza el concepto mismo de justicia social como resultante de la intervención del Estado en el funcionamiento espontáneo de la sociedad para lograr una equidad, la que sólo produce una distorsión en la correcta asignación de los recursos por parte del mercado ${ }^{17}$. Nozick va más allá, hasta afirmar que la justicia distributiva surge sólo del mercado que representa la mejor y más justa distribución posible de recursos entre individuos ${ }^{18}$. Frente a lo anterior Rawls retomará ciertos presupuestos clásicos de la justicia social al concentrar su atención en el principio de igualdad de oportunidades, lo que implica que ciertos bienes sean redistribuidos en una sociedad para lograr equidad, es decir, una base social a partir de la cual el individuo logra desplegar su capacidad de autodeterminación ${ }^{19}$. Prolongando la intención del liberalismo igualitario de Rawls, Dworkin defenderá la perspectiva según la cual la justicia social pasa por equiparar las circunstancias de las personas permitiendo que todas dispongan del mismo capital inicial para liberarlas de las contingencias, haciéndolas de este modo responsables de sus preferencias y méritos individuales ${ }^{20}$. No obstante, para todos estos autores el motivo de los conflictos sociales pasa -directa o indirectamente- por una falta de asignación justa de bienes y recursos, lo cual implica que -en lo fundamental- estos conflictos tienen un origen económico.

Frente a lo anterior, la teoría del reconocimiento de Axel Honneth plantea que los conflictos sociales deben ser comprendidos no a partir de causas económicas, sino que a partir de una experiencia de agravio o humillación moral que moviliza a los individuos a luchar por el reconocimiento ${ }^{21}$. Esta lucha busca obtener la restauración de la moral mancillada de un sujeto fruto de una desconsideración social (missachtung). Consecuentemente, el reconocimiento social permite poner en marcha un proceso de integración que se va logrando a través del reconocimiento recíproco que posibilita -a su vez- a los individuos salir de su invisibilidad y de su condición marginal para insertarse en formas progresivas de socialización. El proceso de integración social se va logrando así en la medida que el individuo sale de su particularismo individualista y marginal, para insertarse en el circulo virtuoso de formas progresivas de socialización que no son sino formas progresivas de reconocimiento de las cuales Honneth identifica tres esferas: la experiencia del amor, del reconocimiento jurídico y de la solidaridad social. Cabe precisar que estas formas progresivas de integración social no son -sino- formas de justicia social que habilitan el acceso a la confianza, a la estima de sí y a la autovaloración, que permiten -en consecuencia- la constitución de la dignidad y de la identidad social de un sujeto como plenamente autónomo y capaz de actuar en una sociedad. Los conflictos sociales surgen precisamente cuando una expectativa de reconocimiento de un sujeto o una minoría se ve defraudada, catalizando un malestar que moviliza formas de lucha social destinadas a conquistar y visibilizar formas de reivindicación de dignidad y respeto social adeudadas.

\section{La otra deuda histórica}

Desde esta perspectiva, se destaca la experiencia histórica de humillación, menosprecio y agravio que moviliza a los mapuches en un conflicto cuyo motor es la búsqueda de reconocimiento por parte del resto de la sociedad en torno el valor de su cultura como digna de respeto y consideración, para así alcanzar una identidad colectiva resuelta y segura de si misma. En efecto, una cierta historiografía ha avanzado su línea de interpretación en orden a considerar la lucha por el reconocimiento como parte de

16 Marx, Karl, Grundrisse der Kritike der Politischen Ökonomie, Berlin, Dietz, 1953, p.20.

17 Hayek, Frederich, Law, Legislation and Liberty: The Mirage Of Social Justice, London, Routledge, 1983.

18 Nozick, Ronald, Anarchy, State and Utopia, New Yersey, Blackwell, 1974.

${ }_{19}$ Rawls, John, Theory of justice, Cambridge, Harvard University Press, 1971.

${ }^{20}$ Dworkin, Ronald, Sovereign Virtue: The Theory and Practice of Equality, Cambridge, Harvard University Press, 2000.

${ }^{21}$ Honneth, Axel, Kampf um Anerkennung, Frankfurt am Main, Suhrkamp Verlag, 1993. 
la deuda histórica con el pueblo mapuche. En efecto, tal como lo expone Rolf Foerster, el enfrentamiento con el colonizador hispano operó como catalizador de la constitución de los mapuches como pueblo entre los siglos XVII y XVIII. ${ }^{22}$ Si la sociedad mapuche en tiempos de paz se caracterizaba por una autoridad política restringida (lonko), cuya legitimidad pasa por el Admapu o conjunto de tradiciones normativas que reglan la vida en común, la sociedad mapuche en tiempos de guerra -o sociedad rechefortalecía sus vínculos de organización política. De este modo, como señala Foerster -siguiendo a José Llincoqueo- a través de los reche no sólo se levantó una oposición al colonizador y sus agentes socializadores -iglesia, encomienda y ejercito-, sino que una complexión política organizada en torno a la conducción y representación asumida por los lonkos que se fue reforzando al interior del mundo mapuche con la génesis de una nueva conciencia política. El establecimiento de "la frontera" en el Bio Bío no sólo fue un acontecimiento geopolítico, sino propiamente político ya que la institución de "los parlamentos" se tradujo en la existencia y representación de dos naciones.

Tal gestación de un sujeto político al interior del mundo mapuche entra en crisis con el advenimiento de la República. "Los mapuches dejaron de ser vistos como un pueblo o nación y comienzan a ser tratados como "ciudadanos chilenos" 23 . Esta iniciativa corresponde a una forma de asimilación cultural, pues "ella se enmarca en una larga tradición etnocentrista, que concibió al indígena como una pueblo sumido en la barbarie por lo que se justificaron distintos intentos de ocupación desde la llegada de los primeros conquistadores españoles hasta la incorporación territorial definitiva por la chilenidad en $1888^{2}{ }^{24}$. De esta forma la política de exclusión económica que operó el régimen de reducciones, estuvo unido, a la vez a una política de "asimilación" de forma que la violencia se ejerció doblemente. Tal como señala Foerster, Jorge Pinto fue el primero en introducir las categorías inclusiónexclusión para caracterizar doblemente este movimiento de despojo material y moral. Dicho de otro modo, una parte del proceso de conquista fue de carácter económico mientras otra parte del proceso de conquista se ejerció sobre los hombres. Frente a ello, si bien los mapuches "lograron adaptarse a la esfera reduccional" 25 , recreando su identidad unida a sus tradiciones culturales, se vieron privados de su posibilidad de autodeterminación.

No obstante, la perdida de soberanía, no fue el resultado sino el punto de partida de un proceso extinción cultural que estuvo dirigido por un esfuerzo del Estado destinado a socializar al pueblo mapuche a través de la instituciones republicanas- salud, educación, policía, lenguaje, derecho, formas de producción- en un esfuerzo destinado a incorporarlo a la nación chilena. Ello va a la par de un menosprecio de las instituciones sociales propias del mundo del pueblo mapuche. Este proceso se vio además reforzando por la migración del campo a la ciudad donde el mapuche queda privado del medio ambiente natural donde su cultura encuentra eficacia simbólica. Este decurso -como señala acertadamente Foerster- "se relaciona con la deuda histórica hacia los pueblos originarios. Es muy diferente su forma y contenido, si la política de reconocimiento se enmarca en el escenario étnico"26.

En efecto, el debate sobre las políticas del reconocimiento del pueblo mapuche, se han enmarcado sobre todo en su reconocimiento constitucional como sujeto político capaz de autodeterminación. No obstante, tal debate omite un estadio previo al reconocimiento jurídico. Concretamente el reconocimiento constitucional se puede transformar en una forma vacía si no presupone a la base un reconocimiento cultural que le da contenido a la afirmación de una identidad como digna de estima o valoración, a partir del cual el pueblo mapuche accede y se afirma, a sí mismo, a través de la mirada del otro. El pasaje de una colectividad de hecho a la calidad de sujeto histórico está implicado precisamente en esta afirmación especular desde la mirada del otro. Desde luego esta demanda

\footnotetext{
22 Foerster, Rolf, “Sociedad mapuche y sociedad chilena: la deuda histórica” en Polis Revista Latinoamericana, 2/2002.

23 Ibid., p.3.

24 Martínez, Christian, "Políticas colonizadoras de Chile en el siglo XIX: la ilusión modernizadora, Araucanía 1813-1913" en Estudios Sociales $N^{\circ}$ 69, Santiago, p.80-81.

25 Ibid., p.3.

26 Ibid., p.4.
} 
de reconocimiento cultural no apunta a la formalización vacía del derecho, sino a un reconocimiento que se materialice en la articulación e institucionalización de agentes socializadores -el lenguaje, la historiografía, la relación con la tierra, la medicina tradicional, la educación, las tradiciones normativas, los ritos, las formas sociales- a partir del cual el pueblo mapuche obtiene la eficacia simbólica de su identidad cultural como única y distinta. Se trata en síntesis de la afirmación del ser mapuche lo que está en juego frente al peligro más importante que enfrenta un pueblo original ante la globalización occidental: el etnocidio.

Tal requerimiento de valoración cultural a partir del cual el mapuche obtiene la eficacia de su identidad como presupuesto para la construcción de un sujeto político ha sido claramente esgrimido por la Coordinadora Arauco-Malleco:"Es reconocido el hecho que nuestro pueblo en su conjunto, producto de las luchas de las comunidades en conflicto ha recuperado la dignidad de ser mapuche, la conciencia de pertenecer a un pueblo que tiene un pasado, presente y futuro común. Elementos esenciales para comenzar el proyecto de liberación mapuche." 27 En efecto, cualquier pretensión política del pueblo mapuche presupone a la base la afirmación de una identidad colectiva. Ella se articula sobre la base de una lucha por el reconocimiento que tiene su origen en una deuda histórica que está a la base de esta demanda social: la experiencia de agravio o menosprecio que se experimenta negativamente como resentimiento, pero que se articula en términos positivos como lucha por la recuperación de la dignidad en tanto conciencia común de constituir una forma de vida única y distinta. Como comenta acertadamente Carlos Pérez: "Pero los problemas de los mapuches deben resolverlos ellos mismos, no los chilenos. Y, creo que esta diferencia, en la que está implicado el concepto de respeto es y debe ser, muy significativa" 28.

Es esta cuestión la que aparece con toda claridad en la siguiente constatación que hace la coordinadora Arauco Malleco "Tienen que pasar muchas generaciones todavía para que haya conciencia política de nuestro pueblo de pertenecer a una nación (...). Los procesos de [asimilación] han sido constantes, han sido muy profundos entonces todavía van a tener que pasar varias generaciones para que nuestra gente asuma su condición, asuma la conciencia política de pertenecer a un pueblo con derechos propios, con derechos que están reconocidos en los organismo internacionales y de los cuales nosotros como una sola voz debemos revindicar" 29 . En un sentido similar el Consejo de Todas las Tierras ha llamado a: "Conformar un movimiento con clara identidad cultural mapuche, y levantar un sentimiento nacional mapuche, mediante distintos símbolos de orden histórico y actual" 30.

\section{Propuesta y consideraciones finales}

En el caso del pueblo mapuche, la teoría del reconocimiento puede ser especialmente productiva para dar cuenta de una cierta economía interna que está tras este conflicto social. Ello no implica, desde luego, abandonar el modelo distributivo de justicia social sino enriquecerlo con una aproximación moral que releve la insatisfacción de este grupo social frente a su invisibilidad nacional, como para dar cuenta de ciertos tipos de demandas que no logran ser resueltas debidamente con el marco de lectura dominante en la actual legislación. No obstante, Honneth afirma una premisa puramente intersubjetiva de la identidad en circunstancias que la identidad individual es indisociable de la pertenencia de un individuo al sistema normativo de carácter objetivo que es la cultura. Por otra parte, lo que está en juego no es tan solo una lucha por el reconocimiento individual, sino de una colectividad: el pueblo mapuche. A partir de lo anterior, es necesario explorar la posibilidad de introducir como correctivo la política multicultural

\footnotetext{
${ }_{27}$ Documento Planteamiento político-estratégico de la Coordinadora de Comunidades en Conflicto Arauco-Malleco, sin fecha (al parecer del año 2000).

${ }_{28}$ Pérez, Carlos, Medio milenio de discriminación al pueblo mapuche, Sociedad Escritores de Chile, Santiago, 1999, página 1.

${ }^{29}$ En ponencia de Pedro Cayuqueo, en FELAA 1999, Santiago, 14 de setiembre del 1999. Citado por Foerster, Rolf, op.cit.

${ }^{30}$ El pueblo mapuche su territorio y sus derechos, Aukíñ Wallmapu Ngulam, Temuco, 1997, pág. 107.
} 
de reconocimiento de Charles Taylor, para quien el reconocimiento de las minorías presupone la continuidad con el presupuesto liberal de igual dignidad de los ciudadanos a la vez que se conjuga con la diferencia que advierte en la identidad singular de un individuo o de una colectividad el fundamento de su valor ${ }^{31}$. No obstante, la tradición liberal estima que las diferencias culturales serían el resultado de elecciones individuales sin advertir la importancia de la cultura al interior del estatuto indiferenciado del Derecho, lo que se traduce en una experiencia de exclusión y desprecio de una minoría frente a una cultura dominante. En este mismo sentido William Kymlicka defiende la idea de que la autonomía y la identidad de un individuo no logra forjarse sino es al interior de usos y costumbres normativos que forman parte de cada cultura ${ }^{32}$. Cultura que para la etnografía de Evans-Pritchard y Levi-Strauss es indisociable de la naturaleza circundante donde una sociedad indígena encuentra su eficacia simbólica ${ }^{33}$. resulta interesante interrogar el texto antropológico del psicoanalista alemán Erik Erikson Childhood and Society. En él Erikson relata la situación de los jóvenes sioux, que durante la colonización en Estados Unidos, se vieron sometidos a una crisis cuando tuvieron que responder a dos sistemas normativos: un sistema normativo impuesto por los colonizadores y, al mismo tiempo, un sistema normativo heredado que todavía existía entre la población nativa. Privados de un sistema normativo que constituía su cultura e instituciones y sin pertenecer completamente a otro sistema, los sioux se sintieron desposeídos, despojados de cierta condición o cierto estatus moral, unido a un sentido "real" u "objetivo" de sí mismo, que hace a un individuo a digno frente a los demás miembros de la sociedad y diferentes al mismo tiempo frente al resto de la sociedad colonizadora. A partir de lo anterior es posible argumentar el carácter objetivo de la identidad individual $-\mathrm{y}$ no puramente intersubjetivo como pretende la teoría del reconocimiento de Honneth- el que resulta de la pertenencia a una institución o sistema normativo de carácter objetivo cuya crisis está unida a la experiencia de opresión (Unterdruck) que puede vivir un individuo como perdida de dignidad y sentimiento humillación asociado a un deterioro del contexto al cual pertenece.

De acuerdo a lo anterior, resulta especialmente interesante elaborar una propuesta normativa de integración social basada en la teoría del reconocimiento. Desde esta perspectiva la protesta frente a la explotación de los recursos naturales, por ejemplo, no pasa necesariamente por consolidar el derecho de propiedad ni concesiones de uso o explotación a favor de los indígenas, sino en buscar la protección del valor cultural asociado al territorio indígena dado que es precisamente en la naturaleza que la identidad de los indígenas encuentra su eficacia simbólica. Así, por ejemplo, el valor e identidad de la machi es indisociable del humedal sagrado (menoko) que le sirve como reserva medicinal, antes que consistir en un punto de captación sobre el cual constituir una concesión o derecho de aprovechamiento de agua. Desde este punto de vista se debe explorar el recurso a otros tipos de políticas públicas, como lo son aquellas organizadas en torno a los instrumentos de planificación territorial para lograr la protección del territorio natural que constituye el contexto cultural a partir del cual el mapuche obtiene su identidad y valor personal. Del mismo modo la ampliación de la educación bilingüe a todos los niños del país, abre al mapuche la posibilidad de afirmarse a si mismo frente a los otros en el contexto de su propio lenguaje. Otro ejemplo es el artículo 10 de la Ley Indígena que requiere un mínimo de diez miembros mayores de edad para constituirse en comunidad indígena, lo que contraviene los usos y costumbres en torno a la constitución del lof y consecuentemente la afectación de la organización sociopolítica fundamental mapuche. Todos ejemplos de casos en que la falta de reconocimiento del otro se traduce en una

\footnotetext{
31 Taylor, Charles, Multiculturalism and the politics of recognition, Princeton, Princeton University Press, 1992.

32 Kymlicka, William, Ciudadanía Multicultural: Una teoría liberal de los derechos de las minorías, Barcelona, Paidós, Estado y Sociedad, 1996.

${ }^{33}$ En este sentido escribe Levi-Strauss en el texto El pensamiento salvaje: "Igualmente que sobre el plan lógico, el operador especifico efectúa el pasaje de una parte hacia lo concreto y lo individual, y de otra parte hacia lo abstracto y el sistema de categorías, al igual que sobre el plan sociológico, las clasificaciones totémicas -en que un animal o especie vegetal se toma como símbolo de la tribu o el individuo- permiten a la vez de definir le estatus de la personas en el seno del grupo y a la vez de dilatar el grupo más allá de su cuadro tradicional”. Levi-Strauss, Claude,1962, La pensée sanvage, Paris, Plon, p.220. Traducción propia.ś.
} 
experiencia de despojó de un cierto referente de sentido, el que se traduce a su vez en una sensación de menosprecio y deterioro de la identidad personal frente al otro.

\section{Bibliografía}

Aylwin, José, Meza-Lopehandía, Matías, \& Yañez, Nancy, Los pueblos indigenas y el derecho. Santiago, LOM Ediciones, 2013.

Bengoa, José, Historia del Pueblo Mapuche (Siglo XIX y XX), Santiago, Chile, LOM ediciones, 2000.

Bengoa José. Historia de un Conflicto. El estado y los mapuches en siglo xx. Santiago, Editorial Planeta Chilena S.A., 1999.

Carilao, Domingo y otros. La socialización del niño mapuche, en el ámbito de la familia, el lof-che y la escuela. Tesis de grado. Universidad Católica de Temuco, Temuco. 1988.

Comisión de Trabajo Autónomo Mapuche, "Informe de la Comisión de Trabajo Autónomo Mapuche", abril 2003. Revisado el 8 de octubre de 2018. Disponible en: http://biblioteca.serindigena.org/libros_digitales/cvhynt/

Comisión de Verdad Histórica y Nuevo Trato, "Informe de la Comisión Verdad Histórica y Nuevo Trato de los Pueblos Indígenas", 25 de junio de 2001. Disponible en: http://www.memoriachilena.cl/602/articles-122901_recurso_2.pdf Revisado el 8 de octubre de 2018.

Curivil, Ramón. Los cambios culturales y los procesos de reetnificación entre los mapuches urbanos, Tesis de Magister, Universidad Academia de Humanismo Cristiano,1999.

Dworkin, Ronald, Sovereign Virtue: The Theory and Practice of Equality, Cambridge, Harvard University Press, 2000.

Erikson, Erik. Childhood and society. New York, W. W. Norton and Company, 1950 Santiago, 1988.

Foerster, Rolf y Montencinos, Sonia. Organizaciones, Lideres, y Contiendas Mapuche (1900 - 1970).

Foertser, Rolf. "El tratado de paz de 1793. Una aproximación a la gramática de la memoria mapuchehuilliche", en Revista Austral de Ciencias Sociales, no 2, Universidad Austral, Valdivia, 1998, pp. 59-68.

González, Héctor. "Propiedad comunitaria o individual. Las leyes indígenas y el pueblo mapuche", en Nütram, Año II, N³, 1986.

Hayek, Frederich, Law, Legislation and Liberty: The Mirage Of Social Justice, London, Routledge, 1983.

Honneth, Axel, Kampf um Anerkennung, Frankfurt am Main, Suhrkamp Verlag, 1993.

Kymlicka, William, Ciudadania Multicultural: Una teoria liberal de los derechos de las minorías, Barcelona, Paidós, Estado y Sociedad, 1996.

Marx, Karl, Grundrisse der Kritik der Politischen Ökonomie, Berlin, Dietz, 1953, p.20.

Montecinos Ximena; Saavedra, Alejandro. Actas del Seminario Educación Intercultural Bilingüe en la región

metropolitana. CONADI Oficina de asuntos indígenas Santiago - Unidad de cultura y educación. Centro de Estudios de la Realidad Contemporánea. Universidad Académica del Humanismo Cristiano. Santiago, 1998.

Nozick, Ronald, Anarchy, State and Utopia, New Yersey, Blackwell, 1974.

Pinto, Julio, De la inclusión a la exclusión. La formación del estado, la nación y el pueblo mapuche, Santiago, Instituto de Estudios Avanzados-Universidad de Santiago,2000.

Levi-Strauss, Claude, La pensée sauvage, Paris, Plon, 1962.

Levi-Strauss, Claude, Race et histoire, Paris, Bontghier,1961.

Rawls, John, Theory of justice, Cambridge, Harvard University Press, 1971.

Salazar, Gabriel, Labradores, Peones y proletarios, Santiago, Ediciones Sur, 1985.

Taylor, Charles, Multiculturalism and the politics of recognition, Princeton, Princeton University Press, 1992.

Torreblanca, José y otros. Revista Iberoamericana de educación. Educación, Lenguas y Culturas. Madrid, Editorial Organización de Estados Iberoamericanos para la Educación, la Ciencia y la Cultura, 1998. 